\title{
Inhaled nitric oxide for neonates with persistent pulmonary hypertension of the newborn in the CINRGl study: time to treatment response
}

Leif D. Nelin ${ }^{1 *}$ and Jim L. Potenziano ${ }^{2}$

\begin{abstract}
Background: Substantial numbers of neonates with hypoxic respiratory failure (HRF) do not immediately respond to inhaled nitric oxide (iNO) and are often labeled as non-responders. This retrospective data analysis assessed time to treatment response in the iNO key registration trial.

Methods: Treatment response was defined as a $\geq 10 \%$ increase in partial pressure of arterial oxygen $\left(\mathrm{PaO}_{2}\right)$ or $a \geq 10 \%$ decrease in oxygenation index $(\mathrm{Ol})$ after initiation of study gas without the need for extracorporeal membrane oxygenation (ECMO). The proportion of patients showing a response at $30 \mathrm{~min}, 1 \mathrm{~h}, 24 \mathrm{~h}$, and $>24 \mathrm{~h}$ after iNO or placebo initiation was calculated and stratified by baseline $\mathrm{PaO}_{2}$ and $\mathrm{Ol}$.

Results: Data from 248 patients (iNO: $n=126$; placebo: $n=122$ ) were included; 66 patients receiving iNO showed improvement in oxygenation without needing ECMO versus 38 receiving placebo. Of the 66 iNO responders, 73\% responded within $\leq 30 \mathrm{~min}, 9 \%$ within $\leq 1 \mathrm{~h}, 12 \%$ within $\leq 24 \mathrm{~h}$, and $6 \%$ after $24 \mathrm{~h}$. Of the 38 patients with improvement in oxygenation without needing ECMO while receiving placebo, 53\% showed improvement within $\leq 30$ min, $16 \%$ within $\leq 1$ h, $29 \%$ within $\leq 24 \mathrm{~h}$, and $3 \%$ after $24 \mathrm{~h}$. Baseline disease severity was not predictive of time to response. Of the 48 patients in the iNO treatment group who were classified as non-responders due to eventual need for ECMO and not included in the analysis of responders, 40 (83\%) had an initial improvement in oxygenation during iNO therapy.

Conclusions: Changes in $\mathrm{PaO}_{2}$ and $\mathrm{Ol}$ after iNO initiation appear to be imprecise biomarkers of response to therapy in neonates with HRF. In some patients treated with iNO, it took up to $24 \mathrm{~h}$ to achieve improvement in oxygenation without need for ECMO, and a majority of those who eventually required ECMO did show an initial improvement in oxygenation during iNO treatment. Thus, reliable, objective, early criteria for iNO response still need to be established, and initial $\mathrm{PaO}_{2} / \mathrm{Ol}$ responses should be interpreted with caution, particularly when considering discontinuing iNO therapy.
\end{abstract}

Keywords: Hypoxic respiratory failure, Inhaled nitric oxide, Oxygenation index, $\mathrm{PaO}_{2}$, Persistent pulmonary hypertension of the newborn

\footnotetext{
* Correspondence: leif.nelin@nationwidechildrens.org

${ }^{1}$ The Research Institute at Nationwide Children's Hospital, 575 Children's

Crossroads, Columbus, $\mathrm{OH}$ 43215, USA

Full list of author information is available at the end of the article
}

(c) The Author(s). 2019 Open Access This article is distributed under the terms of the Creative Commons Attribution 4.0 International License (http://creativecommons.org/licenses/by/4.0/), which permits unrestricted use, distribution, and reproduction in any medium, provided you give appropriate credit to the original author(s) and the source, provide a link to the Creative Commons license, and indicate if changes were made. The Creative Commons Public Domain Dedication waiver (http://creativecommons.org/publicdomain/zero/1.0/) applies to the data made available in this article, unless otherwise stated. 


\section{Background}

An estimated 2\% of all live-born neonates require mechanical ventilation each year in the United States [1], and approximately 35,000 term and near-term neonates require mechanical ventilation because of hypoxic respiratory failure (HRF) [2]. Persistent pulmonary hypertension of the newborn (PPHN) is a common cause of respiratory failure in this population [3]. The risk of mortality in infants $\geq 34$ weeks' gestational age on mechanical ventilation is estimated at $5 \%$; approximately $11 \%$ develop chronic lung disease and approximately $9 \%$ experience serious neurologic complications [3].

Inhaled nitric oxide (iNO), a potent, selective pulmonary vasodilator, is frequently used as adjunctive therapy in neonates with HRF associated with PPHN [3, 4]. The use of iNO has been shown to improve oxygenation [5$7]$, reduce the need for extracorporeal membrane oxygenation (ECMO) $[5,6]$, and reduce the risk of chronic lung disease [5] in newborns with PPHN and HRF. The Clinical Inhaled Nitric Oxide Research Group Investigation (CINRGI) study, the key registration trial of iNO in this patient population, showed that administration of low doses of iNO, initiated at $20 \mathrm{ppm}$ and then titrated down to $5 \mathrm{ppm}$ as tolerated, was associated with a significant reduction in the use of ECMO (38\% in the iNO group vs. $64 \%$ in the placebo group; $p=0.001$ ), a significant increase in the mean (SD) ratio of arterial-to-alveolar oxygen tension (0.10 [0.14] vs. 0.05 [0.13]; $p=0.02)$, and a significant reduction in the incidence of chronic lung disease, as defined by the need for supplemental oxygen at 30 days of age (7\% vs. $20 \%$; $p=$ 0.02) [5]. These findings from the CINRGI trial demonstrated the effectiveness of iNO in this patient population and led to the approval of iNO by the US Food and Drug Administration (FDA) for these patients in 1999.

Although iNO has been shown to improve outcomes in this population, a substantial number of patients still do not have an immediate response to iNO and are often labeled as non-responders. A meta-analysis by Finer and Barrington found that iNO was clearly associated with improvement in oxygenation in infants with HRF [8]. However, the mortality rate for HRF in term and late preterm patients is approximately $11 \%$ and has remained relatively constant since the FDA approval of iNO in 1999 [9]. Therefore, interest is growing in developing rational approaches to treating term and near-term infants that include defining iNO responders so that other therapies, such as ECMO, can be initiated in a timely manner $[4,10-12]$. Indeed, a lack of oxygenation response within $1 \mathrm{~h}$ has been suggested as a criterion for discontinuing iNO [4]. Furthermore, interest in other vasodilators for use in non-responders to iNO has been growing, although good evidence supporting their use is lacking [13-15].
The objective of the current analysis was to determine if there is a clear time to treatment response for term and near-term neonates using data from CINRGI, a placebo-controlled study [5]. We hypothesized that oxygenation responses within $1 \mathrm{~h}$ of starting iNO would not accurately predict the need for ECMO. A post hoc analysis of available data from the CINRGI study, which included patients treated with iNO or placebo, was performed.

\section{Methods \\ Study population}

Details of the design and methodology for the CINRGI study have been previously reported [5]. Briefly, the study included neonates with pulmonary hypertension who required assisted ventilation, had an oxygenation index $(\mathrm{OI}) \geq 25$, were born after 34 weeks' gestation, and were $\leq 4$ days old at the time of inclusion in the study. Neonates urgently requiring ECMO for refractory hypotension or profound hypoxemia were excluded from the study, as were those with a lethal congenital anomaly, substantial bleeding diathesis, active seizures, or history of severe asphyxia. Before randomization, patients were assigned to 1 of 5 pulmonary disease diagnostic categories: meconium aspiration syndrome, idiopathic pulmonary hypertension, pneumonia, respiratory distress syndrome, and lung hypoplasia syndrome. All physicians and nurses who provided care for neonates in the study were blinded to study treatments.

\section{Study design}

The CINRGI study was approved by the institutional review board at each study site, and parents or guardians provided written informed consent. Patients were randomized to treatment with either iNO diluted in nitrogen (INO Therapeutics, Port Allen, LA) or nitrogen gas (Ohmeda, BOC Gases, Murray Hill, NJ) administered via an iNO delivery system into the inspiratory flow of the ventilator circuit. The placebo group received nitrogen. Study gas in both study groups was initiated at $20 \mathrm{ppm}$ and continued for $4 \mathrm{~h}$. After $4 \mathrm{~h}$, the dose was decreased to $5 \mathrm{ppm}$ if the patient's condition was stable, partial pressure of arterial oxygen $\left(\mathrm{PaO}_{2}\right)$ was $\geq 60 \mathrm{mmHg}$, and $\mathrm{pH}$ was $\leq 7.55$. When response criteria were not met, study gas administration continued at $20 \mathrm{ppm}$ and patients were re-evaluated every $4 \mathrm{~h}$ until the criteria were met or they received $24 \mathrm{~h}$ of study gas. During the first $24 \mathrm{~h}$, if the $\mathrm{PaO}_{2}$ dropped to $<60 \mathrm{mmHg}$ when the fraction of inspired oxygen was 1.0 , patients could be returned to the $20 \mathrm{ppm}$ dose. After the first $24 \mathrm{~h}$, patients experienced a dose decrease to $5 \mathrm{ppm}$; this dose was continued until patients achieved a fraction of inspired oxygen of $<0.7$, received $96 \mathrm{~h}$ of study gas, or were 7 days old, whichever came first. Treatment was 
considered a failure when patients could not tolerate the reduced dose at $24 \mathrm{~h}$ or when the study gas could not be discontinued within $96 \mathrm{~h}$. The study gas was discontinued when patients were successfully weaned from it, when they met the failure criteria, or when they required ECMO. In cases requiring ECMO, the study gas continued until ECMO was initiated.

\section{Assessments}

The primary outcome measure assessed in the main study was the use of ECMO in neonates treated with iNO compared with those not treated with iNO [5]. Other key outcomes assessed included improvement in the ratio of arterial partial pressure of oxygen-to-alveolar partial pressure of oxygen, incidence of short- and long-term complications, and death [5]. Although $\mathrm{PaO}_{2}$ and OI data were collected, the relationship between time on iNO and oxygenation responses was not examined in the CINRGI study.

\section{Statistical analysis}

Descriptive statistics for baseline variables were calculated, and the distributions of values between the 2 study groups were tested using a $t$-test for continuous values and a chi-square test for categorical values. The main outcome of interest for the current post hoc analysis was the time from initiation of the study gas to achievement of treatment response, defined as a $\geq 10 \%$ increase in $\mathrm{PaO}_{2}$ or $\mathrm{a} \geq 10 \%$ decrease in OI after initiation of the study treatment without the need for ECMO (standard criteria used to define treatment response at the time of the original CINRGI study). The proportion of patients achieving a successful response at $30 \mathrm{~min}, 1 \mathrm{~h}, 24 \mathrm{~h}$, and $>24 \mathrm{~h}$ after initiation of the study gas was calculated. Response rates at each time point were also stratified by baseline $\mathrm{PaO}_{2}$ and $\mathrm{OI}$ values.

\section{Results}

A total of 248 neonates were enrolled in the original study; 126 patients were assigned to treatment with iNO and 122 were assigned to placebo [5]. The median duration of iNO treatment in the original study was $44 \mathrm{~h}$ [5]. Of the 248 neonates enrolled, 66 (52\%) receiving iNO and 38 (31\%) receiving placebo showed improvement in oxygenation and no need for ECMO. Baseline characteristics of responders in each study group are summarized in Table 1. The placebo group had a higher proportion of male patients than did the iNO group.

Table 1 Baseline demographic and clinical characteristics in patients showing improvement in oxygenation without needing extracorporeal membrane oxygenation

\begin{tabular}{|c|c|c|c|}
\hline Variable & $\begin{array}{l}\text { iNO group } \\
n=66\end{array}$ & $\begin{array}{l}\text { Placebo group } \\
n=38\end{array}$ & $P$ value \\
\hline \multicolumn{4}{|l|}{ Birth weight, kg } \\
\hline Mean (SD) & $3.3(0.55)$ & $3.3(0.65)$ & 0.902 \\
\hline \multicolumn{4}{|l|}{ Age at enrollment, hours } \\
\hline Mean (SD) & $32.1(20.63)$ & $30.8(18.25)$ & 0.748 \\
\hline Male, $n(\%)$ & $28(42.4)$ & $24(63.2)$ & 0.042 \\
\hline Race or ethnic group, $n$ (\%) & & & 0.955 \\
\hline Black & $28(42.4)$ & $14(36.8)$ & \\
\hline Hispanic & $6(9.1)$ & $4(10.5)$ & \\
\hline White & $29(43.9)$ & $18(47.4)$ & \\
\hline Other & $3(4.6)$ & $2(5.3)$ & \\
\hline \multicolumn{4}{|l|}{ Primary pulmonary disease diagnosis, $n$ (\%) } \\
\hline Meconium aspiration syndrome & $23(34.8)$ & $14(36.8)$ & \\
\hline Idiopathic pulmonary hypertension & $21(31.8)$ & $15(39.5)$ & \\
\hline Pneumonia & $15(22.7)$ & $7(18.4)$ & 0.794 \\
\hline Respiratory distress syndrome & $5(7.6)$ & $1(2.6)$ & \\
\hline Lung hypoplasia syndromes & $2(3.0)$ & $1(2.6)$ & \\
\hline \multicolumn{4}{|l|}{$\mathrm{PaO}_{2}, \mathrm{mmHg}$} \\
\hline Mean (SD) & $87.8(73.63)$ & $66.2(41.35)$ & 0.058 \\
\hline \multicolumn{4}{|l|}{ Oxygenation index } \\
\hline Mean (SD) & $28.5^{\mathrm{a}}(15.86)$ & $33.2(15.5)$ & 0.154 \\
\hline
\end{tabular}

iNO inhaled nitric oxide, $\mathrm{PaO}_{2}$ partial pressure of arterial oxygen

${ }^{a}$ The oxygenation index data are missing for 4 patients in the nitric oxide group 
The baseline mean $\mathrm{PaO}_{2}$ value tended to be higher and the baseline mean OI value tended to be lower in the iNO group than the placebo group; however, these differences were not statistically significant.

Of the 66 patients receiving iNO who showed improvement in oxygenation without needing ECMO, 48 (73\%) responded within $30 \mathrm{~min}$ of treatment initiation, $6(9 \%)$ within $1 \mathrm{~h}, 8$ (12\%) within $24 \mathrm{~h}$, and $4(6 \%)$ after $24 \mathrm{~h}$ (Fig. 1). Of the 38 patients receiving placebo who showed improvement in oxygenation without needing ECMO, 20 (53\%) showed improvement within $30 \mathrm{~min}$ of treatment initiation, $6(16 \%)$ within $1 \mathrm{~h}, 11(29 \%)$ within $24 \mathrm{~h}$, and 1 (3\%) after $24 \mathrm{~h}$. An analysis of patients who showed improvement in oxygenation without needing ECMO while receiving iNO or placebo, stratified by baseline OI and time to improvement, showed that disease severity at baseline (as reflected by OI) was not predictive of time to improvement in oxygenation (Fig. 2a and b). An analysis of the patients who had improvement in oxygenation without needing ECMO (ie, responders), stratified by baseline $\mathrm{PaO}_{2}$, showed similar results (data not shown).

In the CINRGI study, 48 of the 126 (38\%) iNO-treated patients eventually required ECMO and were therefore labeled as non-responders. Forty (83\%) of these patients eventually requiring ECMO had an initial response to iNO in terms of oxygenation, with all 40 having a $\geq 10 \%$ increase in $\mathrm{PaO}_{2}$ and/or a $\geq 10 \%$ decrease in OI, signifying an initial oxygenation response to iNO treatment. Interestingly, this group demonstrated a pattern of oxygenation response to iNO treatment similar to that of the iNO responder population described above, despite going on to need ECMO. Of the 40 patients who failed the primary outcome measure but had an initial response to iNO treatment, 22 (55\%) initially responded to iNO within $30 \mathrm{~min}$ of treatment initiation, 7 (18\%) within $1 \mathrm{~h}, 1$ (3\%) within $24 \mathrm{~h}$, and 10 (25\%) after $24 \mathrm{~h}$. The mean (SD) $\mathrm{PaO}_{2}$ at baseline in the 29 patients who showed improvement in oxygenation within $1 \mathrm{~h}$ but eventually required ECMO was significantly lower than

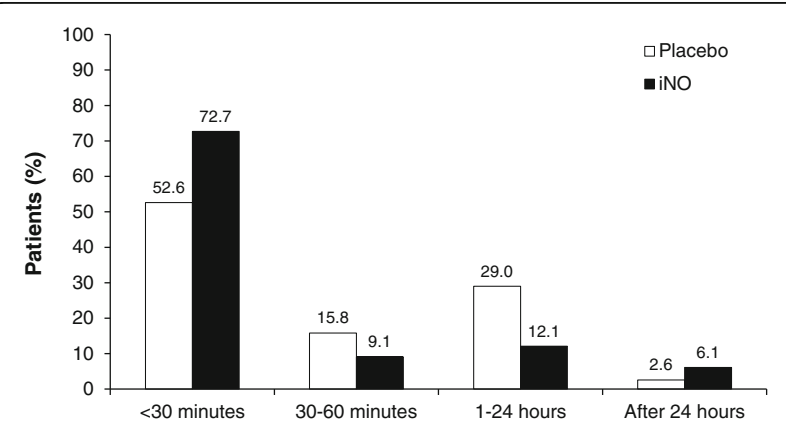

Fig. 1 Time to improvement in oxygenation without need for extracorporeal membrane oxygenation among patients who showed response to treatment. iNO: inhaled nitric oxide

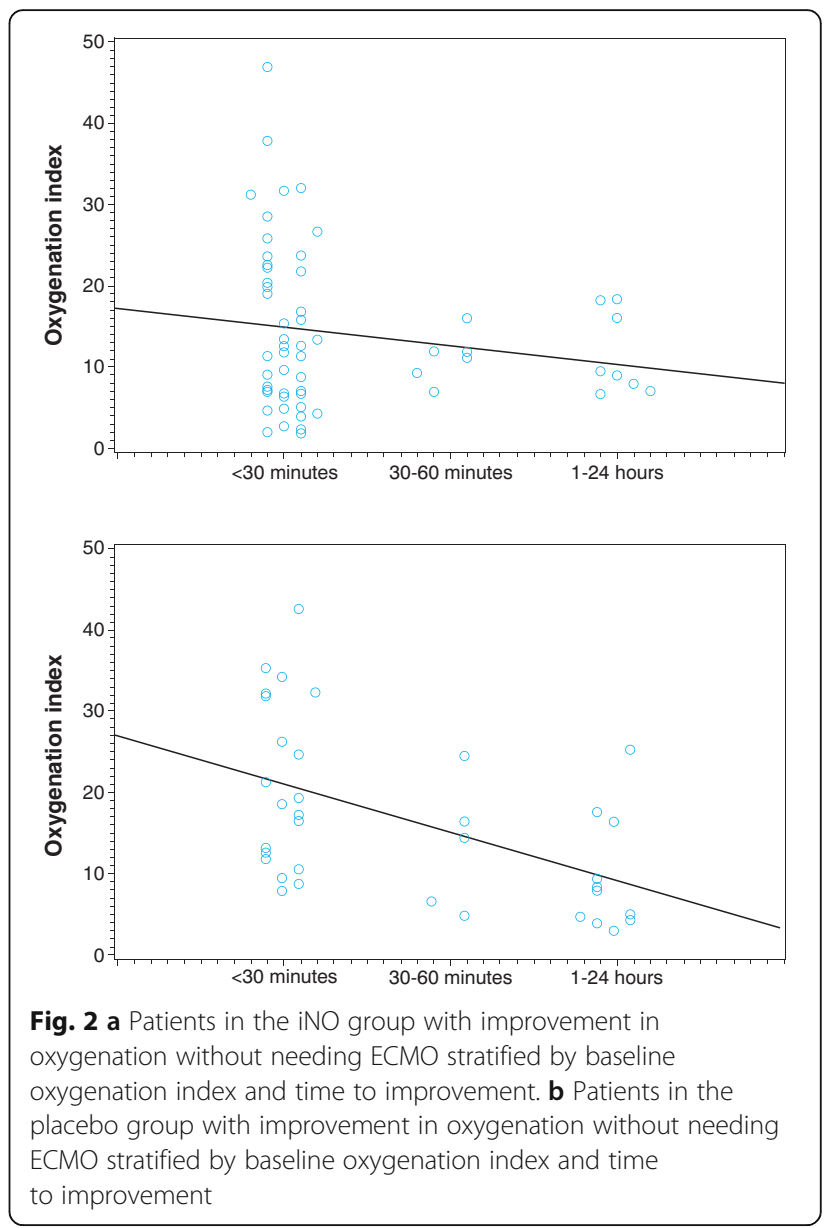

that in patients who had an oxygenation response to iNO treatment and did not require ECMO (46 [22] mmHg vs. 88 [74] mmHg; $p<0.0001)$. The mean (SD) OI at baseline was significantly higher in the iNO group with an initial oxygenation response who then went on to require ECMO than in the iNO-treated responders (47.2 [31.0] vs. 28.5 [15.9]; $p=0.0009)$. Of these 29 patients, $7(24.1 \%)$ received ECMO within $4 \mathrm{~h}$ of initiation of iNO treatment, and 14 (48.3\%) received ECMO within $12 \mathrm{~h}$ of initiation of iNO treatment.

\section{Discussion}

Data from the CINRGI study clearly show a positive effect of iNO treatment on improving outcomes in term and late preterm patients with PPHN and HRF [5]. The CINRGI study was 1 of 2 trials that led to FDA approval of iNO for term and late preterm neonates with HRF for significantly reducing the need for ECMO therapy [5]. The studies used in obtaining FDA approval, including the CINRGI study, had very strict oxygenation eligibility criteria. Given the acuity of these patients, many units have, over time, lowered the oxygenation criteria for 
treating term and late preterm HRF patients with iNO, resulting in an increase in the use of iNO for patients with HRF without a marked change in mortality [9]. Meta-analyses have suggested that only approximately $50 \%$ of patients respond to iNO with an increase in oxygenation [8]. We undertook this post hoc analysis of data from the CINRGI study to determine if the physiologic response to iNO treatment was associated with time after treatment initiation. While many term and late preterm patients with HRF who responded to iNO treatment did so within $60 \mathrm{~min}$, we found that there were patients who continued to exhibit an oxygenation response after $60 \mathrm{~min}$ (late responders), although no statistical difference was observed in the proportion of patients showing a late response in the iNO group versus the placebo group. This finding is consistent with the American Association of Respiratory Care published practice guidelines [4]. However, $60 \mathrm{~min}$ was not a clear, objective delineation of responders and non-responders; some patients in this study responded to treatment after $60 \mathrm{~min}$, and some patients who showed improvement in oxygenation within 60 min of treatment initiation eventually required ECMO therapy. Thus, it seems that oxygenation responses in this population are complicated and can change relatively quickly. It is critical in term and late preterm neonates with HRF to continue monitoring their clinical status and to expect relatively rapid changes in oxygenation and clinical status. Furthermore, these data, taken together with the original outcome data from the CINRGI study, suggest that changes in oxygenation within 30 to $60 \mathrm{~min}$ of initiation of iNO treatment may not be a reasonable biomarker for whether the patient with HRF will ultimately avoid ECMO, the desired clinical outcome for iNO in PPHN. This finding may have important implications for the design of future randomized, controlled studies examining the use of iNO treatment to improve mortality in HRF.

When considering iNO treatment failure, it should be kept in mind that response to iNO treatment is influenced by the adequacy of ventilation and the level of lung recruitment. Kinsella et al. found that the combination of high-frequency oscillatory ventilation (HFOV) and iNO was more successful than either therapy given alone to neonates with HRF [16]. Similarly, Dobyns et al. found that, in pediatric patients with acute HRF, HFOV and iNO treatment improved oxygenation better than either therapy alone [17]. In both of these studies, the authors concluded that enhanced lung recruitment by HFOV enhanced the effects of iNO treatment $[16,17]$. Thus, it is imperative that measures have been undertaken to optimize ventilation and lung recruitment before initiating iNO treatment.

Of the 48 patients treated with iNO who required ECMO in the CINRGI study, 40 had an initial response in terms of improved oxygenation, and 29 had an initial response within $1 \mathrm{~h}$. These patients were more ill at baseline, as evidenced by a lower $\mathrm{PaO}_{2}$ and a greater OI than the group of iNO patients who showed an initial improvement in oxygenation and did not go on to require ECMO. The findings here are consistent with the notion that earlier treatment with iNO (ie, before OI is $>25$, as was the criterion in the CINRGI study) may be beneficial in avoiding ECMO in patients with HRF. For example, a 2-center study comparing early versus late iNO treatment in infants $\geq 35$ weeks' gestation with HRF found that patients treated earlier with iNO were less likely to develop severe HRF (OI >40) [18]; Konduri et al. found that early treatment with iNO (OI 15-25) resulted in fewer patients developing severe HRF, although this approach did not decrease the risk of mortality or ECMO use compared with standard iNO treatment [19]. In a European study of infants with a gestational age $\geq 33$ weeks, early treatment with iNO was associated with a shorter length of mechanical ventilation and shorter length of stay in the neonatal intensive care unit [20]. Furthermore, early treatment with iNO has been found to be cost-effective by reducing the probability that patients will develop severe HRF [21, 22]. It is also reasonable to postulate that earlier initiation of iNO may affect the time to treatment response, and further studies may be needed to determine whether current use of iNO, which often is administered when OI values are lower than those needed to be eligible for the CINRGI study, have an effect on time to treatment response.

Potential limitations of this study should be considered. This retrospective analysis used data from a key clinical randomized, controlled trial of iNO in which the primary outcome measure was the need for ECMO. Our analysis assessed data reflecting the standard of care for treatment of neonates with pulmonary hypertension at the time the CINRGI study was conducted, which may limit interpretation of our results. Also, our analysis did not account for the potential impact associated with concomitant interventions and/or therapies that may have been used in the patients who did not show rapid improvement in oxygenation after initiation of study gas. Nevertheless, this is a unique data set from a relatively large group of patients with all of the necessary physiologic data to address our hypothesis. Some studies stopped iNO treatment in term and near-term patients with HRF after 30 to $60 \mathrm{~min}$ if there was no improvement in oxygenation. Thus, this data set from a study without stopping criteria for iNO treatment based on oxygenation response is necessary to address our hypothesis. All patients who were randomized to iNO in the CINRGI study received iNO treatment until their disease improved, they started ECMO therapy, or they reached $96 \mathrm{~h}$.

This post hoc analysis of data from the CINRGI study suggests that while improvement in oxygenation tended to occur within $1 \mathrm{~h}$ of initiating iNO treatment in the majority 
of term and late preterm infants who responded to treatment, nearly $20 \%$ exhibited response after the first hour of iNO treatment. Also, an initial oxygenation response to iNO treatment within $1 \mathrm{~h}$ in this cohort did not necessarily mean that these patients avoided the need for ECMO.

\section{Conclusions}

In summary, the results demonstrate that oxygenation response to iNO treatment in this patient population is complex and may change rapidly. Furthermore, the CINRGI study data are consistent with the notion that iNO treatment should be started early in the course of HRF for term and late preterm infants. The decision to stop iNO treatment may be complicated and should only be made after carefully considering all aspects of the patient's condition, with particular attention on changes in mean airway pressure and fraction of inspired oxygen levels. These findings highlight the need for further clinical studies to develop a better understanding of factors associated with iNO non-responsiveness and how non-response to iNO affects outcomes to guide future efforts aimed at improving outcomes for term and late preterm patients with HRF.

\section{Additional file}

\section{Additional file 1: CINRGI Study Centers, IRB Names, and Lead} Investigators. (DOCX $20 \mathrm{~kb}$ )

\section{Abbreviations \\ CINRGI: Clinical Inhaled Nitric Oxide Research Group Investigation; ECMO: Extracorporeal membrane oxygenation; FDA: Food and Drug Administration; HFOV: High-frequency oscillatory ventilation; HRF: Hypoxic renal failure; iNO: Inhaled nitric oxide; Ol: Oxygenation index; $\mathrm{PaO}_{2}$ : Partial pressure of arterial oxygen; PPHN: Persistent pulmonary hypertension of the newborn}

\section{Acknowledgments}

Editorial support for preparation of this manuscript was provided by Michael Morren, MBA, RPh, of Peloton Advantage, LLC, and funded by Mallinckrodt Pharmaceuticals. The authors thank Shannon Escalante of Mallinckrodt Pharmaceuticals for assistance with statistical analysis.

\section{Funding}

This study was sponsored by Mallinckrodt Pharmaceuticals (Bedminster, NJ).

\section{Availability of data and materials}

The datasets used and/or analyzed during the current study are available from the corresponding author upon reasonable request. The Clinical Inhaled Nitric Oxide Research Group Investigation (CINRGI) study predated the initiation of the ClinicalTrials.gov registry.

\section{Authors' contributions}

LDN, collection and analysis of the data and writing of the manuscript. JLP, collection and analysis of data, contributions to manuscript writing. Both authors read and approved the final manuscript.

\section{Ethics approval and consent to participate}

The CINRGI study, the results of which were first published in 2000 (Clark RH, et al. N Engl J Med. 2000;342:469-74), was approved by the institutional review board at each study site, as listed in the Additional file 1. Parents or guardians provided written informed consent.
Consent for publication

Not applicable.

\section{Competing interests}

LDN declares that he has no competing interests. JLP is an employee of Mallinckrodt Pharmaceuticals.

\section{Publisher's Note}

Springer Nature remains neutral with regard to jurisdictional claims in published maps and institutional affiliations.

\section{Author details}

'The Research Institute at Nationwide Children's Hospital, 575 Children's Crossroads, Columbus, OH 43215, USA. ${ }^{2}$ Mallinckrodt Pharmaceuticals, Bedminster, NJ, USA.

Received: 21 December 2017 Accepted: 7 December 2018

Published online: 12 January 2019

\section{References}

1. Angus DC, Linde-Zwirble WT, Clermont G, Griffin MF, Clark RH. Epidemiology of neonatal respiratory failure in the United States: projections from California and New York. Am J Respir Crit Care Med. 2001;164:1154-60.

2. Finer NN, Barrington KJ. Nitric oxide therapy for the newborn infant. Semin Perinatol. 2000;24:59-65.

3. Clark RH. The epidemiology of respiratory failure in neonates born at an estimated gestational age of 34 weeks or more. J Perinatol. 2005;25:251-7.

4. DiBlasi RM, Myers TR, Hess DR. Evidence-based clinical practice guideline: inhaled nitric oxide for neonates with acute hypoxic respiratory failure. Respir Care. 2010;55:1717-45.

5. Clark RH, Kueser TJ, Walker MW, Southgate WM, Huckaby JL, Perez JA, et al. Lowdose nitric oxide therapy for persistent pulmonary hypertension of the newborn. Clinical inhaled nitric oxide research group. N Engl J Med. 2000;342:469-74.

6. Neonatal Inhaled Nitric Oxide Study Group. Inhaled nitric oxide in full-term and nearly full-term infants with hypoxic respiratory failure. N Engl J Med. 1997;337(6):434.

7. Davidson D, Barefield ES, Kattwinkel J, Dudell G, Damask M, Straube R, et al. Inhaled nitric oxide for the early treatment of persistent pulmonary hypertension of the term newborn: a randomized, double-masked, placebocontrolled, dose-response, multicenter study. The I-NO/PPHN study group. Pediatrics. 1998;101(3 Pt 1):325-34.

8. Finer N, Barrington KJ. Nitric oxide for respiratory failure in infants born at or near term (review). Cochrane Database Syst Rev. 2006;4:CD000399. https:// doi.org/10.1002/14651858.CD000399.pub2.

9. Clark RH, Ursprung RL, Walker MW, Ellsbury DL, Spitzer AR. The changing pattern of inhaled nitric oxide use in the neonatal intensive care unit. J Perinatol. 2010;30:800-4.

10. Keszler M. Guidelines for rational and cost-effective use of iNO therapy in term and preterm infants. J Clin Neonatol. 2012;1:59-63.

11. Grist $G$, Whittaker $C$, Merrigan $K$, Fenton J, Pallotto E, Lofland G. Defining the late implementation of extracorporeal membrane oxygenation (ECMO) by identifying increased mortality risk using specific physiologic cut-points in neonatal and pediatric respiratory patients. J Extra Corpor Technol. 2009;41:213-9.

12. Karimova A, Brown K, Ridout D, Beierlein W, Cassidy J, Smith J, et al. Neonatal extracorporeal membrane oxygenation: practice patterns and predictors of outcome in the UK. Arch Dis Child Fetal Neonatal Ed. 2009;94:F129-32.

13. Shah PS, Ohlsson A. Sildenafil for pulmonary hypertension in neonates. Cochrane Database Syst Rev. 2011;8:CD005494. https://doi.org/10.1002/ 14651858.CD005494.pub3.

14. Bassler D, Kreutzer K, McNamara P, Kirpalani H. Milrinone for persistent pulmonary hypertension of the newborn. Cochrane Database Syst Rev. 2010;11:CD007802. https://doi.org/10.1002/14651858.CD007802.pub2.

15. Ho JJ, Rasa G. Magnesium sulfate for persistent pulmonary hypertension of the newborn. Cochrane Database Syst Rev. 2007;3:CD005588. https://doi. org/10.1002/14651858.CD005588.pub2.

16. Kinsella JP, Truog WE, Walsh WF, Goldberg RN, Bancalari E, Mayock DE, et al. Randomized, multicenter trial of inhaled nitric oxide and high-frequency oscillatory ventilation in severe, persistent pulmonary hypertension of the newborn. J Pediatr. 1997;131(1 Pt 1):55-62.

17. Dobyns EL, Anas NG, Fortenberry JD, Deshpande J, Cornfield DN, Tasker RC et al. Interactive effects of high-frequency oscillatory ventilation and inhaled 
nitric oxide in acute hypoxemic respiratory failure in pediatrics. Crit Care Med. 2002;30:2425-9.

18. Gonzalez A, Fabres J, D'Apremont I, Urcelay G, Avaca M, Gandolfi C, et al. Randomized controlled trial of early compared with delayed use of inhaled nitric oxide in newborns with a moderate respiratory failure and pulmonary hypertension. J Perinatol. 2010;30:420-4.

19. Konduri GG, Solimano A, Sokol GM, Singer J, Ehrenkranz RA, Singhal N, et al. A randomized trial of early versus standard inhaled nitric oxide therapy in term and near-term newborn infants with hypoxic respiratory failure. Pediatrics. 2004;113(3 Pt 1):559-64.

20. Early compared with delayed inhaled nitric oxide in moderately hypoxaemic neonates with respiratory failure: a randomised controlled trial. The Franco-Belgium Collaborative NO Trial Group. Lancet. 1999;354:1066-71.

21. Konduri GG, Menzin J, Frean M, Lee T, Potenziano J, Singer J. Inhaled nitric oxide in term/late preterm neonates with hypoxic respiratory failure: estimating the financial impact of earlier use. J Med Econ. 2015;18:612-8.

22. Armstrong EP, Dhanda R. Cost-effectiveness of early compared to late inhaled nitric oxide therapy in near-term infants. Curr Med Res Opin. 2010; 26:2795-800.

Ready to submit your research? Choose BMC and benefit from:

- fast, convenient online submission

- thorough peer review by experienced researchers in your field

- rapid publication on acceptance

- support for research data, including large and complex data types

- gold Open Access which fosters wider collaboration and increased citations

- maximum visibility for your research: over $100 \mathrm{M}$ website views per year

At BMC, research is always in progress.

Learn more biomedcentral.com/submissions 